\title{
STUDIES IN CONGESTIVE HEART FAILURE. XXIIII. A CRITICAL STUDY OF METHODS FOR DETERMINING THE CARDIAC OUTPUT IN PATIENTS WITH CARDIAC DISEASE
}

\author{
By ARTHUR GROLLMAN, BEN FRIEDMAN, GURNEY CLARK, AND \\ T. R. HARRISON \\ (From the Department of Medicine of Vanderbilt University, Nashville)
}

(Received for publication April 26, 1933)

The cardiac output of normal persons may be determined by methods the accuracy of which has been adequately demonstrated (4). In patients with congestive heart failure, on the other hand, so many factors intervene that the validity of a method applicable to normal individuals may no longer be assumed. Hitherto, comparatively little work has been done in testing the applicability of various cardiac output methods to patients with heart disease, although data obtained by such methods may be subject to large errors.

In the present investigation we have examined the accuracy of three methods of measuring the cardiac output and ascertained the extent of their applicability to subjects with congestive heart failure. The Burwell and Robinson procedure (3), the venous plateau method ( 7$)$, and the acetylene procedure (4) seemed to us to offer the greatest probability of proving applicable in heart disease. The method of Burwell and Robinson depends upon the equilibration of the patient's blood with a gas mixture obtained by repeated rebreathings. From a comparison of the oxygen content of this blood with that of a sample of arterial blood, the arteriovenous difference is derived. This method assumes that the same physicochemical equilibrium occurs between the blood and the gas obtained by the rebreathing procedure when shaken in a tonometer, as occurs across the pulmonary epithelium during rebreathing. Obviously this physiological equilibration occurs only slowly and may therefore lead to illusory constancy in any case in which pulmonary conditions inhibit (without totally preventing) normal oxygenation of the blood in the lungs. Since such conditions are probably of frequent occurrence in cardiac disease, Burwell and Robinson, realizing these possible sources of error, limited their observations to individuals with normal lungs.

In order to avoid the source of error in the Burwell-Robinson procedure, Harrison, Friedman, and Clark (7) modified it. Their venous plateau method depends upon the use of the lungs for the final equilibration 
instead of a glass tonometer as in the Burwell and Robinson procedure. The patient rebreathes the final gas mixture, and during the rebreathing, samples of "mixed venous" blood are drawn from the femoral artery.

The acetylene procedure (4) is founded upon a principle entirely different from that of these two methods. It depends essentially upon measuring the rate of absorption of a foreign gas across the pulmonary epithelium.

Experiments demonstrating the sources of error occurring in these methods will be presented and the criteria which must be applied for demonstrating their validity in a given patient will be defined. When these criteria are satisfied accurate results may be obtained.

\section{The attainment of homogeneous mixture in a lung-bag system in patients with congestive heart failure}

The measurement of the cardiac output in patients with congestive heart failure is rendered difficult in all methods based upon equilibration of gas mixtures accross the lungs by essentially two factors. The first of these is the change in the mechanical conditions in the lungs which makes it difficult to obtain samples of the gas mixtures which are in true equilibrium with the blood. A second factor is the involvement of the alveoli in a pathological process which prevents the establishment of true equilibrium (in a physicochemical sense) between the alveolar gases and the blood.

A prominent feature in patients with heart disease is the marked pulmonary alteration which mechanically interferes with any rebreathing procedure. The exact nature of the pulmonary lesions need not be described here; suffice it to say that loss of elasticity of the alveolar walls, congestion of the lungs, swelling of the pulmonary epithelium, the presence of edema in the alveoli and bronchioles, and, in some cases, emphysema, combine to increase the residual air and render difficult the attainment of a homogeneous mixture when a patient rebreathes a given gas mixture from a bag. If homogeneity of the contents of the lungs and of the bag is not attained it is obviously impossible to obtain a sample of gas from the bag which is representative of that in equilibrium with the blood.

The Burwell-Robinson, venous plateau and acetylene procedures are all dependent upon attaining complete mixture in a lung-bag system. It was, therefore, necessary to determine the length of time required for obtaining a homogeneous mixture in this system. For this purpose the method of Lundsgaard and Schierbeck (9), used previously by Grollman and Marshall (5), was utilized. The subject rebreathes a mixture of hydrogen in air under the same conditions as in the desired experimental procedure. By analyzing samples of the gas withdrawn simultaneously from the bag and from the mouth one can obtain an indication of the degree of homogeneity in the lung-bag system. The time required is 
about fifteen seconds in normal individuals but is longer in subjects with abnormal lungs.

There exists no definite and universally accepted nomenclature for describing succinctly the clinical condition of a given patient. The term "decompensation," for example, may have a different denotation for different observers. We have included therefore in Table 1 data bearing on the clinical condition of the patients whom we have studied. Comparison of a result in the experimental tables with the clinical description of Table 1 will allow the reader to judge roughly concerning the conclusions to be drawn from the present study.

In Table 2 are given the results obtained in a series of patients showing various degrees of congestive heart failure as defined by the clinical data of Table 1. The patients rebreathed a mixture of hydrogen in air as is customary in measuring the cardiac output by the acetylene method. The volume of gas in the bag (Table 2, column 2) was that which could be inspired without difficulty by the patient (4). The number of respirations and the time after beginning rebreathing when collection of the samples was made are given in columns 3 and 4 .

Since the respiratory quotient is less than unity during rebreathing (due to accumulation of carbon dioxide in the bag which prevents the usual loss of carbon dioxide from the mixed venous blood in the lungs) the hydrogen content of the sample obtained from the mouth is greater than that expired into the bag when homogeneous mixture has been attained in the lung-bag system. A positive difference in the fifth column of Table 2 indicates therefore that mixture has occurred under the conditions of the rebreathing.

The data in Table 2 demonstrate the greater length of time necessary in patients with heart failure than in normal individuals for attaining homogeneous mixture between the air in the lungs and a gaseous mixture contained in a bag. Whereas normal subjects seldom require more than fifteen seconds, the subjects in Table 2 required eighteen seconds in two cases, twenty seconds in three cases, and twenty-five seconds or more in the remaining three. The application of these results to the problem of measuring the cardiac output in such cases will be given later.

\section{Equilibration of gases across the pulmonary epithelium}

The second possible source of error, which must be considered before applying to persons with congestive heart failure a method applicable to normal subjects, is the possible alteration of diffusion through the pulmonary epithelium due to pathological changes. If a change occurs in the lung which diminishes the rate at which a gas can pass into the blood from the alveolar spaces, physicochemical equilibrium may not occur and the method based upon the assumption that it does becomes inapplicable. Although much has been said concerning this possibility in studying cases 


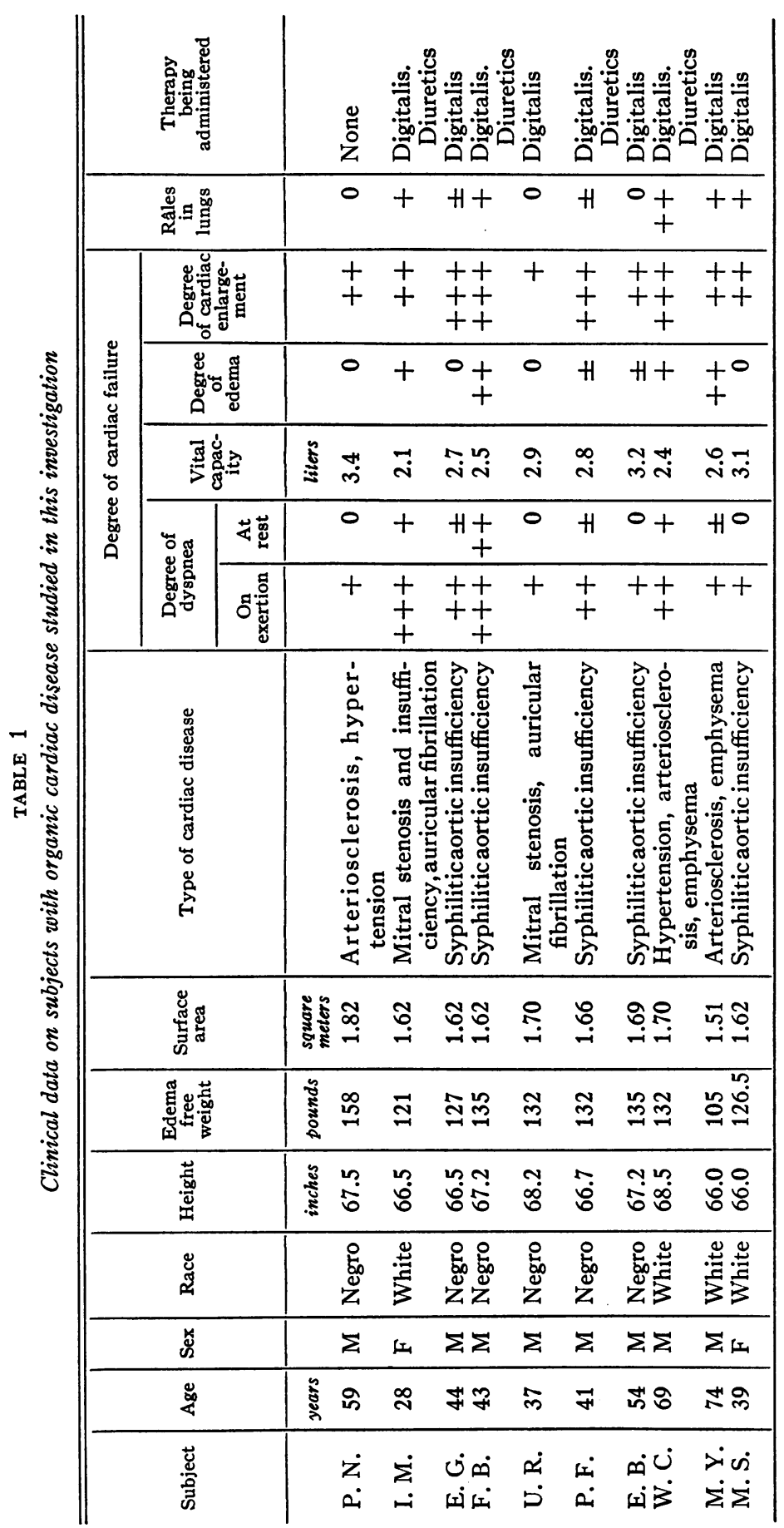


TABLE 2

The time necessary for attaining homogeneous mixture in a lung-bag system

\begin{tabular}{|c|c|c|c|c|c|}
\hline Subject & $\begin{array}{l}\text { Volume } \\
\text { in bag }\end{array}$ & $\begin{array}{l}\text { Number of } \\
\text { respirations }\end{array}$ & $\begin{array}{l}\text { Duration of } \\
\text { rebreathing }\end{array}$ & $\begin{array}{l}\text { Difference between } \\
\text { hydrogen concen- } \\
\text { tration in alveolar } \\
\text { sample and in bag }\end{array}$ & $\begin{array}{c}\text { Time necessary } \\
\text { for attaining } \\
\text { homogeneous } \\
\text { mixture }\end{array}$ \\
\hline P. N. & $\begin{array}{c}\text { liters } \\
1.8\end{array}$ & $\begin{array}{r}7 \\
10 \\
11 \\
13\end{array}$ & $\begin{array}{c}\text { seconds } \\
18 \\
20 \\
21 \\
23\end{array}$ & $\begin{array}{c}\text { per cent of hydrogen } \\
0.00 \\
+0.05 \\
+0.03 \\
+0.03\end{array}$ & $\begin{array}{c}\text { seconds } \\
20\end{array}$ \\
\hline I. M. & 1.2 & $\begin{array}{l}7 \\
6 \\
8 \\
8\end{array}$ & $\begin{array}{l}17 \\
18 \\
22 \\
25\end{array}$ & $\begin{array}{r}-0.03 \\
+0.02 \\
+0.08 \\
+0.01\end{array}$ & 18 \\
\hline E. G. & 1.5 & $\begin{array}{l}7 \\
7 \\
7 \\
9\end{array}$ & $\begin{array}{l}16 \\
18 \\
21 \\
25\end{array}$ & $\begin{array}{l}-0.15 \\
-0.00 \\
+0.01 \\
+0.06\end{array}$ & 20 \\
\hline F. B. & 1.5 & $\begin{array}{r}9 \\
10 \\
12 \\
13\end{array}$ & $\begin{array}{l}18 \\
20 \\
23 \\
26\end{array}$ & $\begin{array}{l}-0.09 \\
-0.02 \\
-0.05 \\
+0.05\end{array}$ & 25 \\
\hline U. R. & 1.5 & $\begin{array}{r}8 \\
9 \\
10\end{array}$ & $\begin{array}{l}17 \\
18 \\
20\end{array}$ & $\begin{array}{l}-0.06 \\
+0.00 \\
+0.01\end{array}$ & 18 \\
\hline P. F. & 1.2 & $\begin{array}{l}9 \\
8 \\
8 \\
9\end{array}$ & $\begin{array}{l}19 \\
23 \\
26 \\
28\end{array}$ & $\begin{array}{r}-0.10 \\
-0.12 \\
0.00 \\
0.00\end{array}$ & 26 \\
\hline E. B. & 1.3 & $\begin{array}{r}7 \\
8 \\
10 \\
10\end{array}$ & $\begin{array}{l}16 \\
19 \\
21 \\
23\end{array}$ & $\begin{array}{r}-0.04 \\
0.00 \\
+0.01 \\
+0.01\end{array}$ & 20 \\
\hline W. C. & 1.2 & 15 & 50 & -0.10 & $\begin{array}{l}\text { Incomplete } \\
\text { mixture }\end{array}$ \\
\hline
\end{tabular}

of heart failure, it is ordinarily relatively less important than the factor of inadequate mixture, which has just been discussed.

The influence of a pathological condition on diffusion through the lung can be obtained from an analysis of the degree of oxygen saturation of the arterial blood. The fact that significant anoxemia occurs only in severe cases of congestive heart failure is an indication that this is a result only of extreme modifications from normal.

It is necessary to consider the possibility of failure to obtain a true equilibrium in cases in which oxygen deficiency of the arterial blood exists. 
In the "oxygen Fick" methods in which it is necessary to secure equilibrium between the gas in the blood and that in a bag, the difference in tension between the two may not be great. Nevertheless any impediment to the passage of oxygen across the pulmonary epithelium may lead to erroneous results. It was this possibility which led Burwell and Robinson to apply their method to normal individuals only.

One of the fundamental assumptions of the acetylene method is the occurrence of true physicochemical equilibrium between this gas in the alveoli and in the blood. That equilibrium occurs in persons with normal circulatory systems and even in some cases of decompensated heart disease was demonstrated by Baumann and Grollman (2) and by Grollman, Proger, and Dennig (6). In one case (senile emphysema with chronic congestive failure) the former authors failed to observe its occurrence. This failure was attributed to an inability to obtain mixture in the lung-bag system and was therefore apparent and not real. Unless one obtains an actual alveolar sample, one cannot judge whether equilibrium has occurred in the lungs by comparison of the gas obtained with a sample of arterial blood. So far as measurement of the cardiac output is concerned, the question is purely academic whether equilibrium has occurred or whether failure to attain it is due to failure to obtain a true alveolar sample. Regardless of the cause, the method is inapplicable in such a case.

In Figures 1, 2, 3, and 4 are reproduced typical experiments demonstrating the relation of the concentrations of acetylene in the blood and in the gas mixtures rebreathed. Two patients (Figs. 1 and 2) rebreathed an acetylene-air mixture from a rubber bag as is usual in measuring the cardiac output. At certain intervals samples of arterial blood and a gas sample from the bag were collected and their acetylene contents determined as described by Grollman, Proger, and Dennig (6). It will be noted in

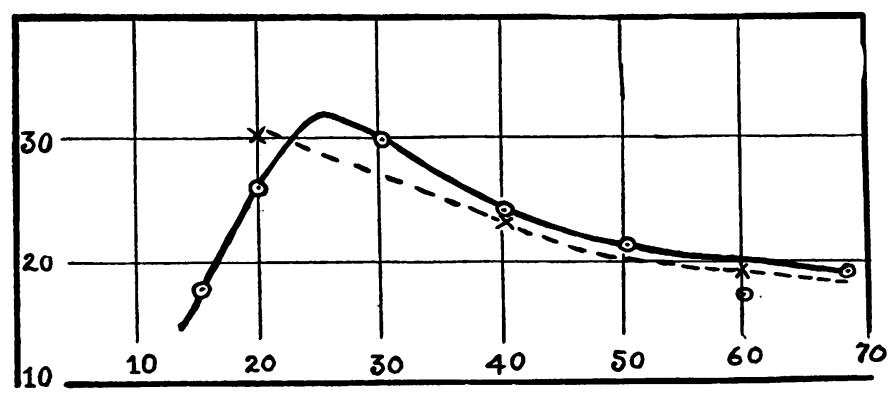

Fig. 1. A Comparison of the Acetylene Content of the Alveolar Air and the Arterial Blood While Rebreathing from a Rubber Bag. SUbJECT E. G. (SeE Table 1).

Ordinates represent the acetylene tension in millimeters of mercury; the abscissae represent the time in seconds after beginning the rebreathing.

$\odot$ Blood samples. $X$ Gas samples. 


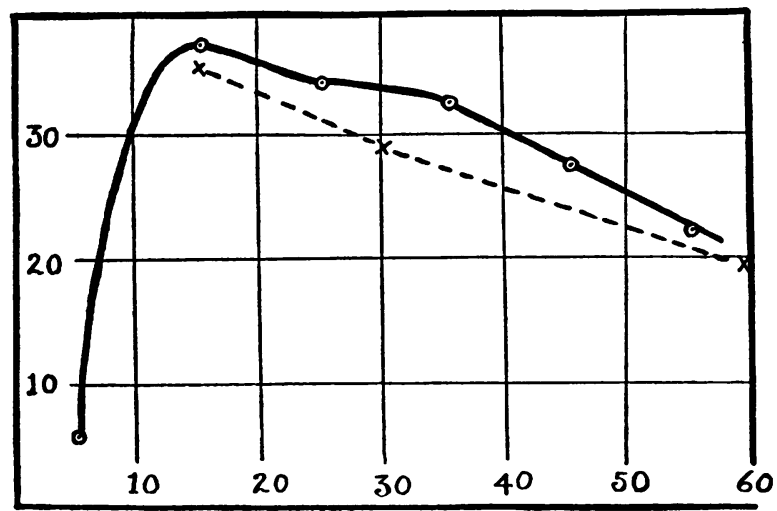

Fig. 2. A Comparison of the Acetylene Content of the Alveolar Air and the Arterial Blood While Rebreathing from a Rubber Bag. SubJECT J. M. (SEE TABLE 1).

Ordinates represent the acetylene tension in millimeters of mercury; abscissae, the time in seconds after beginning the rebreathing.

$\odot$ Blood samples.

X Gas samples.

Figure 1 that there is complete concordance between the amounts of acetylene in the blood and in the bag at twenty seconds after beginning the rebreathing and thereafter. Since this subject could not mix in a period of time less than twenty seconds as seen in Table 2 , the low content of acetylene in the samples of blood collected at fifteen and twenty seconds is to be attributed, not to failure to attain equilibrium between the acetylene of the alveoli and the blood, but to the fact that it required twenty seconds to establish a uniform concentration of gas in the lung-bag system. The remainder of the curve is evidence against the existence in this patient of

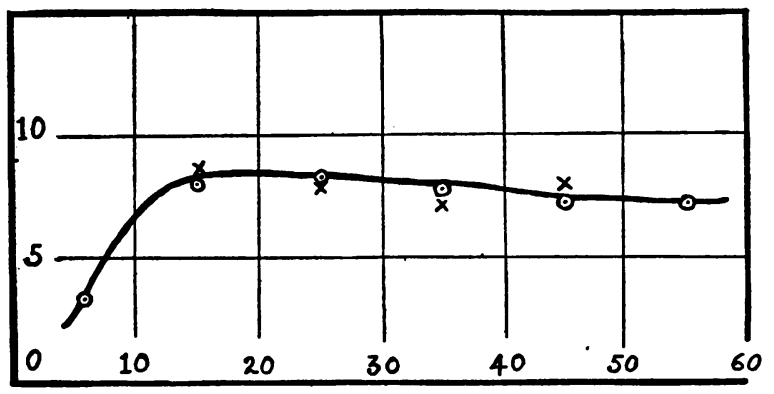

Fig. 3. A Comparison of the Acetylene Content of the Alveolar Air and the Arterial Blood While Rebreathing from a Spirometer. SubJECT I. M. (SEE TABLE 1).

Ordinates represent the acetylene tension in millimeters of mercury; abscissae, the time in seconds after beginning the breathing.

$\odot$ Blood samples.

X Gas samples. 


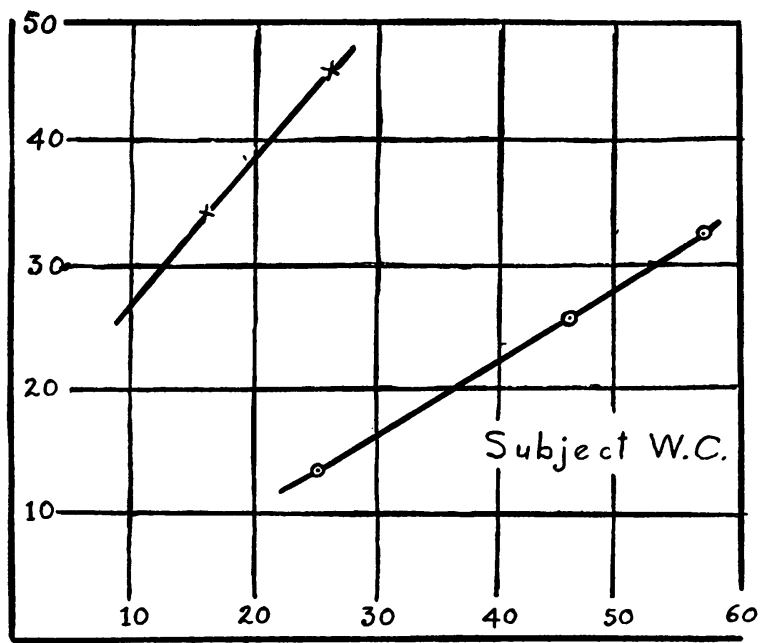

Fig. 4. A Comparison of the Acetylene Content of the "Alveolar" Air and the Arterial Blood While Breathing from a Spirometer. Subject W. C. (See Table 1).

Ordinates represent the acetylene tension in millimeters of mercury; abscissae, the time in seconds after beginning the breathing.

$\odot$ Blood samples.

X Gas samples.

an impediment to the passage of acetylene across the pulmonary epithelium which might interfere with the attainment of equilibrium between the gas in the lungs and in the blood.

The curves of Figure 2 were obtained similarly to those of Figure 1 . At five seconds, the acetylene concentration in the blood was very low, for insufficient time had elapsed since beginning of rebreathing to allow entrance into the alveoli of sufficient amounts of acetylene. After fifteen seconds mixture in the lung-bag system occurred so that the acetylene content of the blood and of the alveoli was parallel. The concentrations in the blood were higher, however, due to the fact that it requires five to ten seconds for the blood to travel from the lungs to the peripheral artery from which it is drawn. If one allows for this $(2,6)$, there results an identity of the curves of the concentrations in the alveoli and in the blood which demonstrates the existence of true physicochemical equilibrium. In Figure 1, there is also a tendency for the acetylene concentrations to be higher in the blood than in the alveoli but in this case the more gradual slope of the curve prevents this from manifesting itself prominently in the samples collected after forty seconds.

The studies of Figures 1 and 2 as well as previous ones of Grollman and his coworkers require the time necessary for the passage of the blood from the lungs to the peripheral artery to be taken into consideration. As is evident from the curves of Figures 1 and 2 and from the results of Baumann and Grollman (2), this possible source of error is negligible 
being only one or two per cent. This smallness results from the relatively small drop in acetylene concentration which is taking place in the bag (Figs. 1 and 2). The assumption involved need not be made, however, if a constant alveolar concentration is maintained. This is accomplished by having the subject inspire at a constant rate from a spirometer containing an acetylene-air mixture. At given intervals forced expirations are made of which alveolar samples are collected. The results of such an experiment on I. M. are given in Figure 3. The concentrations of acetylene in the alveoli and in the blood lie on a uniform curve after. fifteen seconds, the time necessary for substituting the gas mixture for the air in the lungs.

Patients I. M. and E. G. were both cases of congestive heart failure (Table 1) and in them apparently the transport of acetylene across the lungs was sufficiently rapid to ensure equilibrium, despite the fact that there was a slight degree of arterial anoxemia in both subjects. The greater ease of attaining equilibrium between the blood and alveoli in the case of acetylene in comparison with oxygen, is what one might predict on strictly physical grounds. Indeed, it may be said (in view of the experiments just cited and those previously reported) that it is improbable that interference with diffusion in the lung is ever the limiting factor of the acetylene method. Because of its high solubility and its small molecular weight the tension of acetylene in the blood is the same as that in the alveoli to which this blood is exposed. But if conditions exist in which part of the lungs are fibrosed, consolidated, collapsed, or so markedly edematous as to prevent its entrance and, therefore, the passage of acetylene into the blood, the acetylene method cannot measure the blood flowing through these portions of lungs.

One encounters subjects in whom analysis of the acetylene content of the blood shows a smaller concentration than is present in the supposed "alveolar" air. An example is shown in Figure 4, which illustrates the lack of relation between the acetylene contents of the blood and of the "alveolar" samples. In another similar experiment, the same patient inspired a mixture of gas, the acetylene tension of which was $54.4 \mathrm{~mm}$., but whose arterial blood after breathing 55 seconds contained only $29.4 \mathrm{~mm}$. Mixing as tested on this patient (W. C., Table 2) was incomplete even after 50 seconds rebreathing. The discordance in the acetylene content of "lung air" and blood as observed in this patient cannot be attributed, therefore, to any impermeability of the pulmonary epithelium but is due to an inability to obtain a true alveolar sample.

\section{The Burvall-Robinson procedure}

On the basis of the experiments already cited we can define the conditions under which a given cardiac output method based on respiratory maneuvres is applicable and the methods whereby its applicability can be tested. 
The Burwell-Robinson procedure consists essentially in rebreathing repeatedly from a bag in order to obtain a gas in equilibrium with the mixed venous blood. Not only must mixture in the lung-bag system be ensured but sufficient time must be allowed thereafter for the blood to alter. the composition of the gas in the bag. The circulation time cannot be exceeded and hence one is limited to a period of time about thirty seconds (in cases of congestive heart disease) in which to carry out the rebreathing. The process can be carried out repeatedly, however, and in this way one may in normal individuals finally obtain a mixture in true equilibrium with the mixed venous blood. Unfortunately, as has previously been indicated (4), constancy of the final mixture cannot (as has often been done in the past) be taken as a proof of equilibration. A patient with a large volume of residual air can replace the air in his lungs partially during the preliminary rebreathing and dilute the gas in the bag to a certain extent only. This was the source of error in a number of earlier methods.

TABLE 3

The oxygen content of two bags during alternate rebreathings

Subject P. F. (Table 1)

\begin{tabular}{c|c|c}
\hline \multirow{2}{*}{ Number of rebreathings } & \multicolumn{2}{|c}{ Oxygen content } \\
\cline { 2 - 3 } & Bag 1 & Bag 2 \\
\cline { 2 - 3 } 4 & per cent & per cent \\
5 & 4.95 & 3.76 \\
6 & 4.87 & \\
8 & 4.40 & \\
9 & 4.17 & 3.85 \\
11 & 4.15 & \\
12 & & \\
\hline
\end{tabular}

The experiment cited in Table 3 demonstrates how delusive constancy of the composition of the bag mixture may be. The patient in this experiment (P. F., Table 1) rebreathed alternatively from bags 1 and 2 as in the Burwell-Robinson method, the bags initially having contained mixtures of different oxygen contents. After nine rebreathings the oxygen content of bag 1 was constant and equal to 4.16 per cent. Bag 2 , on the other hand, was little affected after the fourth rebreathing and had an oxygen content even after the eleventh rebreathing of only 3.85 per cent. Both of these bags could obviously not be in equilibrium with the mixed venous blood and hence the supposition of their equilibration with the patient's blood might lead to an erroneous result. It must be remembered also that due to the steepness of the oxygen dissociation curve of blood at the degree of oxygen saturation of the mixed venous blood even slight differences in oxygen tension cause a considerable difference in the oxygen content from which, in turn, is calculated the cardiac output. 
The extent to which the source of error just described may invalidate attempts to obtain a gas mixture in equilibrium with the mixed venous blood is further demonstrated in Table 4. In this experiment the patient,

TABLE 4

Changes in the oxygen content of the bag during rebreathings in a patient with congestive heart failure (E. G., Table 1)

\begin{tabular}{|c|c|c|c|c|c|c|c|c|}
\hline \multirow{2}{*}{$\begin{array}{c}\text { Experi- } \\
\text { ment } \\
\text { number }\end{array}$} & \multirow{2}{*}{$\begin{array}{l}\text { Number } \\
\text { of wash } \\
\text { breaths }\end{array}$} & \multirow{2}{*}{$\begin{array}{c}\text { Time } \\
\text { for } \\
\text { washing }\end{array}$} & \multicolumn{2}{|c|}{ Sample 1} & \multicolumn{2}{|c|}{ Sample 2} & \multicolumn{2}{|c|}{ Sample 3} \\
\hline & & & $\begin{array}{l}\text { Time of } \\
\text { collection }\end{array}$ & $\begin{array}{l}\text { Oxygen } \\
\text { content }\end{array}$ & $\begin{array}{l}\text { Time of } \\
\text { collection }\end{array}$ & $\begin{array}{l}\text { Oxygen } \\
\text { content }\end{array}$ & $\begin{array}{l}\text { Time of } \\
\text { collection }\end{array}$ & $\begin{array}{l}\text { Oxygen } \\
\text { content }\end{array}$ \\
\hline & & seconds & seconds & per cent & seconds & per cent & seconds & per cent \\
\hline 1 & 1 & 5 & 20 & 4.27 & 24 & 4.27 & 28 & 4.19 \\
\hline 2 & 2 & 5 & 20 & 3.99 & 25 & 3.99 & 30 & 3.91 \\
\hline 3 & 3 & 7 & 27 & 3.23 & 30 & 3.30 & 34 & 3.21 \\
\hline 4 & 4 & 7 & 23 & 1.41 & & & 28 & 3.56 \\
\hline 5 & 4 & 9 & 29 & 3.38 & 34 & 3.28 & 38 & 3.34 \\
\hline
\end{tabular}

E. G., rebreathed from a bag containing 1.2 liter of nitrogen. Samples were taken at various times during rebreathing. The number of the preliminary "wash" breaths were varied (column 1) in order to vary the oxygen contents of the lung-bag system in the different experiments. The results demonstrate the marked effect which preliminary washings have on the final composition of the gas in the bag. This was observed also by Burwell and Robinson (3). The results also demonstrate the extremely small changes in oxygen content of the bag which can occur during the breathing of mixtures varying as much as one per cent in composition. The rise in oxygen content (in the $3 \mathrm{~d}$ experiment) and the absence of a decrease (in the first and second experiments) of the oxygen content between the collections of the first and second samples are due to inadequate mixture in the lung-bag system. The times in the 5th, 7th and 9th columns refer to that which elapsed after beginning the washing. Actual mixture occurs only after the beginning of rebreathing, and hence fifteen seconds (in the first and second experiment), or sixteen seconds (in the 4th experiment), do not suffice for attaining homogeneous mixture in the lung-bag system at the time of collection of the first sample from the bag.

In order to be certain that the value of a given experiment is not destroyed by the illusive constancy described, it is necessary to approach the final equilibrium with various oxygen contents in the bag. After preliminary rebreathing the patient should rebreathe a given mixture and two samples should be taken after adequate mixture has been attained and before recirculation has begun. It may be advisable to measure the oxygen content with an accuracy greater than \pm 0.01 per cent in order to detect small changes such as are masked in Table 4 in which the results are accurate only to about \pm 0.05 per cent. 
Another procedure which may possibly avoid the source of error under discussion is one which was employed by Burwell and Robinson. Their subjects rebreathed alternately into two bags, the one having an oxygen tension below and the other an oxygen tension above that of the mixed venous blood. In their normal subjects the oxygen tension of the two bags became identical. We have verified their observations in several patients with cardiac disease, but have found others, especially cases of luetic aortic insufficiency, in whom the final values differed markedly as in Table 3 . Obviously the results obtained by this method, in patients with heart failure, are open to grave errors unless one ensures the absence of all the vitiating factors just described. Other so-called "Fick" oxygen or carbon dioxide methods are even more liable to error in such patients.

\section{The venous plateau method}

In applying this method one must consider the possible sources of error outlined in connection with the Burwell-Robinson method in obtaining the gas mixture used in the final rebreathing.

In drawing blood from the femoral artery certain precautions must, however, also be observed. In the first place ample time must elapse to allow mixture between the gas in the bag and in the lungs to take place during the final rebreathing. Samples of blood must be drawn either before or within ten seconds after the patient stops rebreathing, otherwise mixture of partially aerated blood with mixed venous blood may give a plateau which is not representative of the true mixed venous blood. Nor can the patient continue to rebreathe after the completion of a circulation time unless the composition of the rebreathed gas be maintained constant, for example, by allowing the patient to breathe from a spirometer containing gas identical in composition with that in the bag after the final rebreathing.

Despite the theoretical applicability of this method for permitting the prolongation of the rebreathing time, it is impracticable because anoxemia (particularly in patients with congestive heart disease) causes extreme discomfort and may initiate an attack of cardiac pain in persons with coronary disease or aortic insufficiency. Anoxemia may in fact cause marked reduction in cardiac output with consequent prolongation of the circulation time in diseased hearts. Blood samples taken more than five to ten seconds after cessation of the rebreathing may therefore give a plateau which in no way represents that of the mixed venous blood. The plateau corresponding to the mixed venous blood, to be reliable, must occur in the blood of the femoral artery about ten seconds after adequate mixture in the lungbag system has occurred. Before this time the mixed venous blood will lose oxygen if the patient has been "overwashed" in the preliminary "wash breaths" or will take it up if this washing has been insufficient. Only after homogeneous mixture has occurred does the blood reflect the 
composition of the gas mixture in the bag. Correlation of the time at which an oxygen-plateau in the blood occurs with that of the stage of rebreathing is, therefore, of great importance.

A more detailed discussion of the possible sources of error in the Burwell-Robinson and venous plateau methods will be given in a future publication (7).

\section{The acetylene method}

The validity of the underlying assumptions of the acetylene method has been described in detail elsewhere (4) and need not be repeated. In applying the method to cases with congestive heart failure one must consider the three fundamental requirements of the method: (1) Do the samples taken for analysis represent the gas which is in equilibrium with the blood traversing the lungs? (2) Does the gas in the alveolar air enter into equilibrium with the blood? (3) Is the rebreathing procedure completed before the time of a complete circulation of the blood?

As shown in Table 2 it is necessary to prolong the preliminary rebreathing of the acetylene mixture longer in cases of congestive heart failure than in normal individuals before taking the first sample. If the sample is taken before mixture occurs the resultant cardiac output will be false and may be as much as fifty per cent greater or less than the true value. The question of attaining equilibrium across the pulmonary epithelium as already stated seldom, if ever, is involved in applying the acetylene method. Care must be taken, however, not to continue rebreathing beyond a circulation time; otherwise the estimate of the cardiac output will be too low.

In applying the acetylene method in congestive heart failure, how can its applicability be tested without undertaking the laborious work of determining the various factors just outlined? Taking three samples for analysis instead of two suffices for this purpose. The apparatus previously described (4) has been altered to provide another capillary tube which permits collection of the third sample. In cases of congestive heart disease the samples are taken preferably at 20,25 , and 30 seconds after beginning the rebreathing. The samples taken at 20 and 25 seconds are used to calculate one value and those taken at 25 and 30 are used for another. If these agree within the limits of the experimental technical errors one is assured that the assumptions underlying the applicability of the method are valid and that the result is accurate. In all measurements this procedure, involving as it does little extra work, is suggested even in cases in which the applicability of the method can be taken for granted.

In Figure 5 is reproduced an experiment illustrating these points. The patient ( $\mathrm{P}$. N., $c f$. Table 1) could bring mixture about, as shown in Table 2 , in twenty seconds. Samples collected at 18 and 23 seconds gave an apparent cardiac output of 4.25 liters, a value too high because the first sample was taken at 18 seconds when mixture was not quite complete and, 
had, therefore, a higher content of acetylene than was present in the alveoli and in equilibrium with the blood. When samples were taken at 20 and 25 seconds and at 25 and 30 seconds, values were obtained which agreed within the limits of the accuracy of the analytical methods employed. The average of these values ( 3.8 liters) was the correct cardiac output of this patient under the condition of the experiment. When the samples were taken at 30 and 35 seconds, the estimation was too low ( 3.1 liters), because blood containing acetylene had returned to the lungs. In the cases of congestive heart failure which we have studied, recirculation was evident after 30 seconds. This circulation time as observed in these pathological cases is longer than that observed (4) in normal persons due to the greater velocity of the normal blood flow. ${ }^{1}$

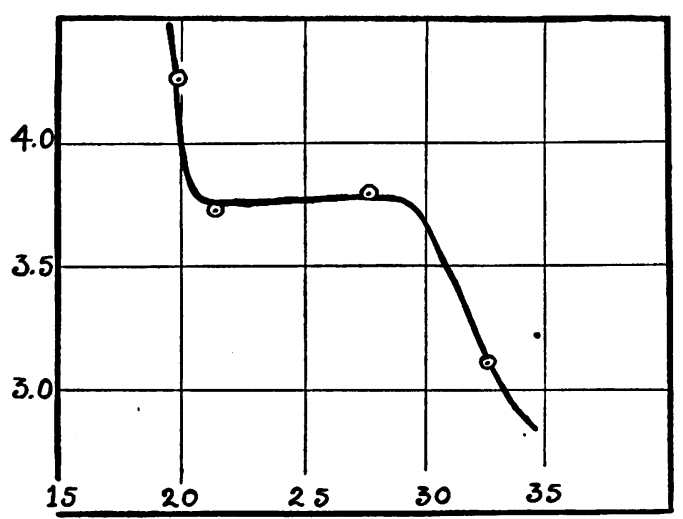

Fig. 5. The Effect of Varying the Time of Sampling on the Apparent Cardiac Output as Obtained by the Acetylene Method. Subject P. N. (NOT BASAL).

The ordinates represent the apparent cardiac output in liters per minute; the abscissae the average time of collection of the two samples used in determining the cardiac output. The plateau represents the true cardiac output.

\section{Comparison of results by the different methods}

The diversity in principles upon which the acetylene method (foreign gas principle) and the Burwell-Robinson and venous plateau methods (oxygen Fick principle) are based gives importance to a comparison of results obtained by these methods when applied to the same patient. In a previous paper, Harrison, Friedman and Clark (7) have shown the excellent

${ }^{1}$ All discussions of the circulation time in the present paper refer obviously only to man. It is well known (4) that the relative circulatory rates in the smaller mammals is greater than it is in man. Hence it is not surprising that Starr and Collins (Am. J. Physiol., 1933, civ, 650) should have found an appreciable return of blood to the heart in 15 seconds in dogs. Their conclusions are obviously inapplicable to man. 
agreement obtained by the various methods in normal subjects. This may be taken as added evidence for the accuracy with which the cardiac output in normal subjects may be measured by these methods. In Table 5 are

TABLE 5

A comparison of results obtained by the Burwell-Robinson, venous plateau, and acetylene methods as applied to patients with congestive heart failure

\begin{tabular}{|c|c|c|c|c|c|c|c|}
\hline \multirow[b]{2}{*}{ Subject } & \multirow{2}{*}{$\begin{array}{c}\text { Oxygen } \\
\text { consumption }\end{array}$} & \multicolumn{2}{|c|}{$\begin{array}{l}\text { Acetylene } \\
\text { method }\end{array}$} & \multicolumn{2}{|c|}{$\begin{array}{l}\text { Burwell-Robinson } \\
\text { method }\end{array}$} & \multicolumn{2}{|c|}{$\begin{array}{l}\text { Venous plateau } \\
\text { method }\end{array}$} \\
\hline & & $\begin{array}{c}\text { Arterio- } \\
\text { venous } \\
\text { oxygen } \\
\text { difference }\end{array}$ & $\begin{array}{l}\text { Cardiac } \\
\text { output }\end{array}$ & $\begin{array}{c}\text { Arterio- } \\
\text { venous } \\
\text { oxygen } \\
\text { difference }\end{array}$ & $\begin{array}{l}\text { Cardiac } \\
\text { output }\end{array}$ & $\begin{array}{c}\text { Arterio- } \\
\text { venous } \\
\text { oxygen } \\
\text { difference }\end{array}$ & $\begin{array}{l}\text { Cardiac } \\
\text { output }\end{array}$ \\
\hline & cc. per minute & cc. per liter & $\begin{array}{l}\text { lilers per } \\
\text { minute }\end{array}$ & cc. per liter & $\begin{array}{l}\text { liters per } \\
\text { minute }\end{array}$ & cc. per liter & $\begin{array}{c}\text { liters per } \\
\text { minute }\end{array}$ \\
\hline $\begin{array}{l}\text { U. R. } \\
\text { M. Y. } \\
\text { E. B. } \\
\text { M. S. } \\
\text { P. F. } \\
\text { E. G. } \\
\text { P. N. } \\
\text { I. M. }\end{array}$ & $\begin{array}{l}198 \\
170 \\
233 \\
215 \\
212 \\
263 \\
258 \\
180\end{array}$ & $\begin{array}{l}90 \\
50 \\
71 \\
65 \\
60 \\
81 \\
69 \\
84\end{array}$ & $\begin{array}{l}2.2 \\
3.4 \\
3.3 \\
3.3 \\
3.6 \\
3.2 \\
3.7 \\
2.1\end{array}$ & $\begin{array}{l}94 \\
50 \\
61 \\
60 \\
57\end{array}$ & $\begin{array}{l}2.1 \\
3.4 \\
3.8 \\
3.5 \\
3.7\end{array}$ & $\begin{array}{l}90 \\
50 \\
68 \\
67 \\
62\end{array}$ & $\begin{array}{l}2.2 \\
3.4 \\
3.4 \\
3.2 \\
3.4\end{array}$ \\
\hline
\end{tabular}

given a series of results obtained in patients with congestive heart disease. The procedures were performed at one sitting. The results agree within the limits of the experimental errors involved and add further evidence of the validity of the theoretical considerations now discussed and the accuracy of the results obtained.

Relatively few values of the cardiac output in congestive heart failure are to be found in the literature in which the necessary precautions have been taken to demonstrate the applicability of the method to the patient under investigation. In view of the small number of cases which we have studied (Table 5) no final conclusion concerning the cardiac output in cardiac disease seems warranted. Of the eight patients cited in Table 5, the cardiac index (4) is reduced in five and within normal limits in the remainder. This does not necessarily imply, however, that the blood supply to the tissues in these cases is adequate, for under the disturbed conditions in the body, particularly in the presence of edema (8), the normal blood supply may still be inadequate for proper supply of the metabolic requirements of the tissues. During exertion, moreover, the cardiac output in these patients may be markedly reduced from the normal (1). We have not yet found patients with congestive failure and abnormally great cardiac output.

\section{Choice of methods}

As to the relative merits of using one or another of the methods studied, the laboriousness of the Burwell-Robinson and venous plateau methods 
both to the patient and to the investigator renders them inferior to the relatively simple acetylene procedure. In persons with normal arterial oxygen saturation the method of taking three samples, as advocated above, for the acetylene method should exclude the possibility of error. With care, moreover, the method will be found to be applicable to a large percentage of subjects with advanced cardiac disease and with mild congestive failure. In those subjects in whom the method is not applicable, the venous plateau method may be applied. Unfortunately, it is in these very cases that the pitfalls inherent in the latter method occur and great care and labor are required to avoid them. A further study of these cases is contemplated.

\section{SUMMARY}

A critical study has been made of the possible sources of error of the Burwell-Robinson, venous plateau and acetylene methods for measuring the cardiac output which may invalidate the results obtained when applying them to patients with congestive heart failure. The methods to be used for detecting and avoiding these errors are indicated. Results as obtained by these different methods are given.

It is a pleasure to express our appreciation to Dean W. S. Leathers for interest in the work and for a grant of money which made our collaboration possible. We are also indebted to Dr. C. S. Burwell for his helpful criticism and advice during the present study.

\section{BIBLIOGRAPHY}

1. Bansi, H. W., and Groscurth, G., Ztschr. f. Kreislaufforsch., 1930, xxii, 657. Die Kreislaufleistung während und nach der Arbeit beim Gesunden und kranken Menschen.

2. Baumann, H., and Grollman, A., Ztschr. f. klin. Med., 1930, cxv, 41. Utber die theoretischen und praktischen Grundlagen und die klinische Zuverlässigkeit der Acetylenmethode zur Bestimmung des Minutenvolumens.

3. Burwell, C. S., and Robinson, G. C., J. Clin. Invest., 1925, i, 47. A Method for the Determination of the Amount of Oxygen and Carbon Dioxide in the Mixed Venous Blood of Man.

4. Grollman, A., The Cardiac Output of Man in Health and Disease. Charles C. Thomas, Publisher, Springfield, Ill., 1932.

5. Grollman, A., and Marshall, E. K., Jr., Am. J. Physiol., 1928, 1xxxvi, 110. The Time Necessary for Rebreathing in a Lung-Bag System to Attain Homogeneous Mixture.

6. Grollman, A., Proger, S., and Dennig, H., Arch. f. exper. Path. u. Pharmakol., 1931, clxii, 463. Zur Bestimmung des Minutenvolumens mit der Acetylenmethode bei Arbeit bei normalen und kranken Menschen.

7. Harrison, T. R., Friedman, B., and Clark, G. In press.

8. Harrison, T. R., and Pilcher, C., J. Clin. Invest., 1930, viii, 259. Studies in Congestive Heart Failure. I. The Effect of Edema on Oxygen Utilization.

9. Lundsgaard, C., and Schierbeck, K., Am. J. Physiol., 1923, 1xiv, 210. Studies on the Mixture of Air in the Lungs with Various Gases. I. 